\title{
Analisis Pendapatan dan Tingkat Kesejahteraan Petani Bawang Merah Lokal Topo di Kelurahan Afa-Afa Kecamatan Tidore Utara Kota Tidore Kepulauan
}

\author{
Linda Baharuddin ${ }^{1}$ dan Munawir Muhammad ${ }^{2}$ \\ 1 Program Studi Agribisnis FAPERTA UMMU, Universitas Muhammadiyah Maluku Utara. Ternate. Indonesia, \\ Email : lindabaharuddin99@gmail.com; munawirmuhammad2012@yahoo.com \\ ${ }^{{ }}$Korespondensi : Munawir Muhammad, Universitas Muhammadiyah Maluku Utara, Ternate, Indonesia, \\ Email : munawirmuhammad2012@yahoo.com
}

\begin{abstract}
ABSTRAK
Bawang merah lokal Topo merupakan salah satu sumberdaya genetik spesifik Maluku Utara yang pada awalnya dibudidayakan di Kelurahan Topo ini kemudian dikenal dengan nama Bawang Merah Topo menurut bahasa lokal. Penelitian ini bertujuan untuk: (1) Menganalisis pendapatan petani bawang merah lokal Topo di Kelurahan Afa-afa Kecamatan Tidore Utara Kota Tidore Kepulauan. (2) Menganalisis tingkat kesejahteraan rumah tangga bawang merah lokal Topo di Kelurahan Afa-afa Kecamatan Tidore Utara Kota Tidore Kepulauan. Jumlah responden petani Bawang Merah Lokal Topo dalam penelitian ini yaitu sebanyak 32 orang. Metode analisis data yang digunakan dalam penelitian ini adalah analisis kuantitatif dan deskriptif kualitatif. Hasil penelitian menunjukkan bahwa: (1) Rata-rata penerimaan yang diperoleh petani bawang merah lokal Topo di kelurahan Afa-afa sebesar Rp 6.879.484/tahun, dengan biaya produksi rata-rata sebesar Rp 1.629.149, sehingga rata-rata pendapatan yang diperoleh petani bawang merah lokal topo sebesar Rp 5.250.334/tahun. (2) Bawang merah lokal Topo layak diusahakan oleh petani responden di kelurahan afa-afa layak setelah diketahui nilai R/C Ratio sebesar 4,22. Berdasarkan hasil penelitian rumah tangga petani bawang merah lokal Topo di Kelurahan Afa-afa Kecamatan Tidore Utara Kota Tidore Kepulauan termasuk dalam klasifikasi sejahtera yaitu sebesar 93,75 persen.
\end{abstract}

Keyword: Bawang Merah Lokal Topo, Pendapatan, Kesejahteraan

\section{PENDAHULUAN}

Bawang merah merupakan salah satu komoditi sayuran yang memiliki nilai ekonomi tinggi ditinjau dari sisi pemenuhan konsumsi nasional, sumber penghasilan petani, dan potensinya sebagai penghasil devisa negara (Nurhapsa, 2015). Tanaman ini telah melekat erat dalam budaya dan kuliner masyarakat Maluku Utara. Sambal khas "colo-colo mantah" terdiri bawang merah, rica/cabai, dan tomat sebagai pendamping hidangan utama adalah manisfestasi dari pentingnya komoditas ini dalam kehidupan masyarakat Maluku Utara (Anonim, 2018)

Berdasarkan data Badan Pusat Statistik (BPS) Maluku Utara tahun 2015, luas panen bawang merah Kota Tidore Kepulauan seluas 125 Ha dan jumlah produksi bawang merah Kota Tidore Kepulauan sebesar 58,40 ton. Berdasarkan data Badan Pusat Statistik (BPS) Maluku Utara tahun 2017 luas panen bawang merah Kota Tidore Kepulauan seluas 37 Ha dan jumlah produksi bawang merah Kota Tidore Kepulauan sebesar 176 kuintal (17,6 ton). Jadi produksi bawang merah Kota Tidore Kepulauan mengalami penurunan dari tahun 2015 sebesar 58,40 ton menjadi 17,6 ton ditahun 2017.

Berdasarkan data Badan Pusat Statistik (BPS) Kota Tidore Kepulauan tahun 2017, produksi bawang merah, khususnya Kecamatan Tidore Utara menempati urutan kedua dengan luas panen dan produksi bawang merah terbanyak setelah kecamatan Oba Selatan. Kelurahan Afa-afa adalah salah satu sentra produksi bawang merah di Kecamatan Tidore Utara Kota Tidore Kepulauan. Petani ditempat ini membudidayakan salah satu varietas bawang merah yaitu, bawang merah lokal Topo.

Menurut Sugihono (2010), bawang merah lokal Topo punya nilai historis yang lekat dengan masyarakat Kota Tidore, Provinsi Maluku Utara. Bawang merah Topo merupakan salah satu sumberdaya genetik spesifik Maluku Utara yang menjadi simbol kebanggaan budaya lokal masyarakat pulau Tidore. Dihabitat aslinya, bawang tersebut dibudidayakan oleh petani Tidore beratus-ratus tahun yang lalu hingga sekarang dengan kondisi agroekosistem dataran tinggi. Kondisi lahan tanam 
merupakan dataran medium-tinggi $\geq 700 \mathrm{~m}$ dpl. Pertanaman di lereng-lereng hutan/kebun campuran (pala, cengkeh), kemiringan lereng terjal $\geq 45 \%$ dengan kondisi sering berkabut.

Budidaya bawang merah lokal Topo dilakukan oleh petani di Kelurahan Afa-afa, terletak didataran dataran tinggi, dan pertanaman dilakukan pada lereng-lereng, serta lokasi penanaman yang jauh dari pemukiman atau tempat tinggal petani, namun hal ini tidak menyurutkan semangat mereka untuk tetap membudidayakan varietas asli pulau Tidore ini. Menurut Muhammad dan Ekaria (2019), strategi yang paling tepat untuk pengembangan bawang merah lokal Topo Kecamatan Tidore Utara pada masa yang akan datang adalah menghadapi tingkat persaingan yang cukup tinggi, terutama persaingan dengan komoditas bawang merah dari luar daerah seperti bawang merah Bima Brebes, Bawang merah Medan, dan lain-lain. Dari data yang diperoleh sebagian petani beralih menanam komoditas bawang merah varietas selain bawang lokal Topo.

Tingginya persaingan yang dirasakan petani bawang merah lokal Topo, akan mempengaruhi tingkat pendapatan dan kemampuan petani dalam mencukupi kebutuhan dasar rumah tangganya. Menurut Thresia (2017), pendapatan yang tinggi selalu diharapkan petani dalam menghasilkan produksi pertaniannya, untuk mendapatkan pendapatan maksimum petani harus dapat meningkatkan produksi dan dapat menekan biaya produksi, oleh karena itu petani harus mampu menyediakan input usahatani secara efisien sehingga hasil yang diperoleh memberikan keuntungan yang cukup besar bagi petani. Terkait kondisi yang dialami petani inilah, membuat penulis tertarik untuk meneliti tentang analisis pendapatan dan tingkat kesejahteraan petani bawang merah lokal Topo di Kelurahan Afa-afa Kecamatan Tidore Utara Kota Tidore Kepulauan.

Berdasarkan uraian diatas, penelitian ini bertujuan untuk: (1) Menganalisis pendapatan petani bawang merah lokal Topo di Kelurahan Afa-afa Kecamatan Tidore Utara Kota Tidore Kepulauan. (2) Menganalisis tingkat kesejahteraan rumah tangga bawang merah lokal Topo di Kelurahan Afa-afa Kecamatan Tidore Utara Kota Tidore Kepulauan.

\section{METODE PENELITIAN}

\subsection{Tempat dan Waktu}

Penelitian ini dilaksanakan di Kelurahan Afa-afa, Kecamatan Tidore Utara, Kota Tidore Kepulauan. Waktu penelitian ini akan dilaksanakan pada bulan Januari sampai Februari 2020. Penentuan lokasi penelitian dilakukan secara sengaja (purposive) dengan pertimbangan bahwa Kelurahan Afa-afa adalah salah satu sentra produksi bawang merah di Kecamatan Tidore Utara Kota Tidore Kepulauan.

\subsection{Metode Pengambilan Sampel}

Populasi dalam penelitian ini adalah seluruh petani bawang lokal Topo di Kelurahan Afa-afa Kecamatan Tidore Utara Kota Tidore Kepulauan. Sampel yang digunakan dalam penelitan ini adalah seluruh petani bawang lokal Topo di Kelurahan Afa-afa Kecamatan Tidore Utara Kota Tidore Kepulauan. Jumlah populasi dalam penelitian ini adalah sebanyak 32 petani. Sehingga penelitian ini merupakan penelitian dengan sampel jenuh (sampel sensus). Menurut Arikunto (2002), apabila subjek dalam penelitian kurang dari 100, maka lebih baik subjek diambil seluruhnya. Berdasarkan pendapat tersebut, sampel dalam penelitian ini sebanyak 32 petani.

\subsection{Teknik Pengumpulan Data}

Data yang dipergunakan dalam penelitian ini adalah data primer dan data sekunder. Data primer diperoleh dengan mewawancarai secara langsung petani bawang merah lokal Topo dengan menggunakan daftar pertanyaan atau kuesioner yang telah disediakan. Data sekunder diperoleh dari berbagai literatur yang ada sesuai dengan topik penelitian seperti publikasi dari lembaga-lembaga terkait.

\subsection{Metode analisis data}

Metode analisis yang digunakan dalam penelitian ini adalah analisis kuantitatif dan deskriptif kualitatif. Analisis kuantitatif digunakan untuk mengetahui besarnya pendapatan petani bawang merah lokal Topo, sedangkan analisis deskriptif kualitatif digunakan untuk menggambarkan objek penelitian pada saat sekarang yaitu tingkat kesejahteraan rumah tangga petani bawang merah lokal Topo di Kelurahan Afa-afa Kecamatan Tidore Utara Kota Tidore Kepulauan 
Menurut Soekartawi (2003), analisis pendapatan digunakan untuk menghitung penerimaan, total biaya dan pendapatan, secara matematis dirumuskan sebagai berikut.

1. Analisis Penerimaan

$\mathbf{T R}=\mathbf{P} \times \mathbf{Q}$

Dimana :

TR = Total Revenue $/$ total penerimaan (Rp)

$\mathrm{P} \quad=$ Price/Harga $(\mathrm{Rp})$

$\mathrm{Q}=$ Quantity/Jumlah (Rp)

2. Analisis Biaya

\section{TC $=$ TFC + TVC}

Dimana :

$\mathrm{TC}=$ Total Cost/biaya total (Rp)

$\mathrm{TFC}=$ Total Fixed Cost/Total Biaya Tetap (Rp)

TVC = Total Variabel Cost/Total Biaya Variabel (Rp)

3. Analisis Pendapatan

\section{Pd $=$ TR-TC}

Dimana :

$\mathrm{Pd}=$ Pendapatan (Rp)

$\mathrm{TR}=$ Total Revenue/total penerimaan $(\mathrm{Rp})$

$\mathrm{TC}=$ Total Cost/biaya total (Rp)

Menurut Sari et al (2014), guna mengetahui apakah usahatani tersebut menguntungkan atau merugikan, maka dilakukan analisis $\mathrm{R} / \mathrm{C}$ rasio. Analisis Return Cost (R/C) ratio merupakan perbandingan (ratio atau nisbah) antara penerimaan (revenue) dengan biaya (cost). Nilai R/C rasio diperoleh menggunakan rumus di bawah ini :

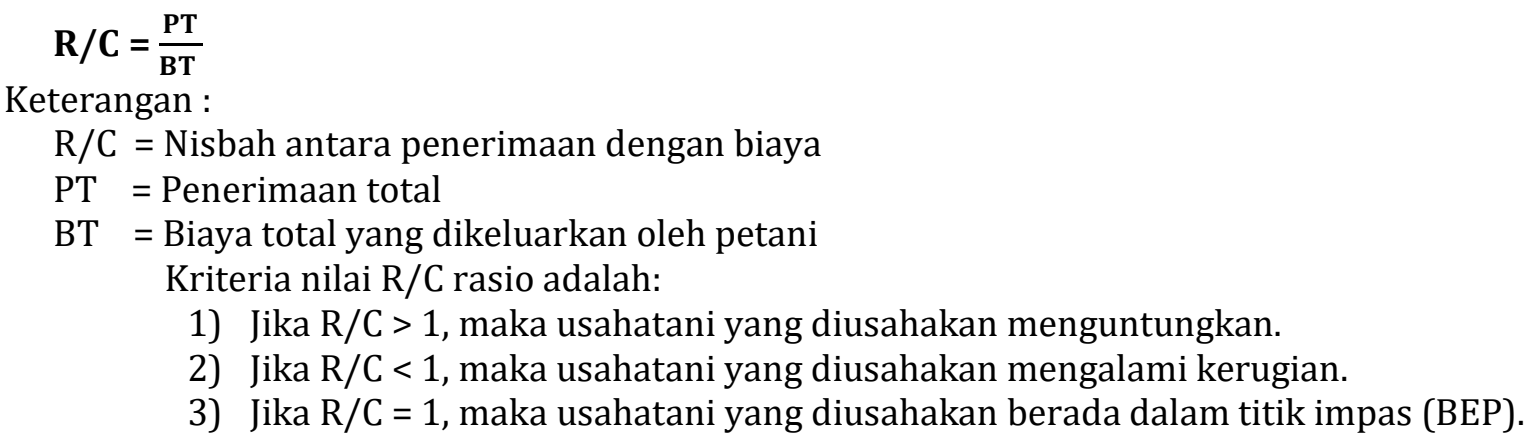

\subsection{Tingkat Kesejahteraan Rumah Tangga Petani}

Berdasarkan penelitian Disha (2019), tingkat kesejahteraan petani diukur menggunakan tujuh indikator menjadi kriteria BPS (Badan Pusat Statistik) 2014, meliputi kependudukan, kesehatan dan gizi, pendidikan, ketenagakerjaan, pola konsumsi, perumahan dan lingkungan, sosial dan lain-lain.

Menurut Disha (2019), klasifikasi kesejahteraan yang digunakan terdiri dari dua klasifikasi yaitu rumah tangga sejahtera dan belum sejahtera. Skor tingkat klasifikasi pada tujuh indikator kesejahteraan dihitung berdasarkan pedoman penentuan range skor. Rumus penentuan range skor adalah :

$$
\mathbf{R S}=\frac{\mathbf{S k T}-\mathbf{S k R}}{\mathrm{JKI}}
$$

\section{Keterangan :}

RS = Range skor

SkT $=$ Skor tertinggi $(7 \times 3=21)$

SkR = Skor terendah $(7 \times 1=7)$

7 = Jumlah indikator kesejahteraan BPS (kependudukan, kesehatan dan gizi, pendidikan, ketenagakerjaan, pola konsumsi atau pengeluaran rumah tangga, perumahan dan lingkungan, dan sosial lainnya) 
$3=$ Skor tertinggi dalam indikator BPS (baik)

$2=$ Skor sedang dalam indikator BPS (sedang)

$1=$ Skor terendah dalam indikator BPS (kurang)

$\mathrm{JKl} \quad=$ Jumlah klasifikasi yang digunakan (2)

Menurut Disha (2019), hasil perhitungan berdasarkan rumus tersebut diperoleh range skor (RS) sama dengan tujuh, sehingga tingkat kesejahteraan rumah tangga petani adalah sebagai berikut:

(1) Jika skor antara 7-14 berarti rumah tangga petani belum sejahtera.

(2) Jika skor antara 15-21 berarti rumah tangga petani sejahtera.

\section{HASIL DAN PEMBAHASAAN}

\subsection{Biaya Produksi}

Biaya usahatani adalah semua pengeluaran yang dipergunakan dalam usahatani. Biaya usahatani dibedakan menjadi dua yaitu biaya tetap dan biaya variabel. Biaya tetap adalah biaya yang besarnya tidak tergantung pada besar kecilnya produksi yang akan dihasilkan. Berdasarkan hasil penelitian yang diperoleh, biaya tetap yang digunakan oleh petani di Kelurahan Afa-afa berasal dari biaya penyusutan alat diantaranya hand Sprayer, drum dan caplak, sedangkan biaya variabel yang digunakan oleh petani di Kelurahan Afa-afa berasal dari biaya pupuk yang digunakan diantaranya NPK, Urea, Petrovita, Biotaplus, TSP dan obat-obatan yang digunakan yaitu decis. Total biaya produksi usahatani bawang merah lokal Topo di Kelurahan Afa-afa diperoleh dengan menjumlahkan biaya tetap dan biaya variabel. Rata-rata biaya produksi usahatani bawang merah lokal Topo di Kelurahan Afa-afa dapat dilihat pada Tabel 1 dibawah ini.

Tabel 1. Rata-rata Biaya Produksi Usahatani Bawang Merah Lokal Topo MT I, MT II dan MT III di Kelurahan Afa-afa

\begin{tabular}{|c|c|}
\hline Komponen Biaya & Rata-rata/Petani \\
\hline Biaya Tetap (FC) & 261,100 \\
\hline \multirow{3}{*}{ 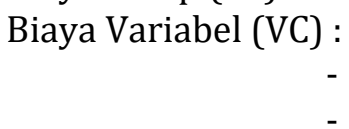 } & 276,375 \\
\hline & 342,174 \\
\hline & 749,500 \\
\hline Total Biaya (TC) & $1,629,149$ \\
\hline
\end{tabular}

Berdasarkan Tabel 1 diatas dapat dijelaskan bahwa total biaya yang dikeluarkan petani responden di Kelurahan Afa-afa dalam satu tahun sebesar Rp 1,629,149. Biaya total yang dikeluarkan petani responden berasal rata-rata biaya tetap sebesar $\mathrm{Rp} 258,861$ dan rata-rata biaya variabel musim tanam I sebesar Rp 276.375, musim tanam II sebesar Rp 342,174 dan musim tanam III sebesar Rp 749,500.

\subsection{Penerimaan Usahatani Bawang Merah Lokal Topo}

Penerimaan adalah hasil perkalian harga jual dengan jumlah produksi petani responden. Ratarata jumlah produksi pada ketiga musim tanam dan rata-rata Penerimaan dapat dilihat pada Tabel 2 dibawah ini.

Tabel 2. Rata-rata Penerimaan Usahatani Bawang Merah Lokal Topo MT I, MT II dan MT III di Kelurahan Afa-afa

\begin{tabular}{cccc}
\hline MT & $\begin{array}{c}\text { Harga/Kg } \\
\text { (Rp) }\end{array}$ & $\begin{array}{c}\text { Produksi } \\
\text { (Kg) }\end{array}$ & $\begin{array}{c}\text { Penerimaan } \\
\text { (Rp) }\end{array}$ \\
\hline I & 50.000 & 30,69 & 1.534 .375 \\
II & 50.000 & 43,65 & 2.182 .609 \\
III & 50.000 & 63,25 & 3.162 .500 \\
\hline Total & & & $\mathbf{6 . 8 7 9 . 4 8 4}$ \\
\hline
\end{tabular}

Berdasarkan hasil penelitian harga jual bawang merah Lokal Topo pada saat penelitian adalah Rp 50.000 per kilogram, rata-rata produksi bawang merah Lokal Topo yang dihasilkan pada musim tanam I sebesar 30,69 kilogram, sehingga penerimaan rata-rata petani responden pada musim tanam I 
adalah sebesar Rp 1.534.375. Rata-rata rata-rata produksi bawang merah Lokal Topo yang dihasilkan pada musim tanam II sebesar 43,65 kilogram, sehingga penerimaan rata-rata petani responden pada musim tanam II adalah sebesar Rp 2.182.609. Rata-rata rata-rata produksi bawang merah Lokal Topo yang dihasilkan pada musim tanam III sebesar 63,25 kilogram, sehingga penerimaan rata-rata petani responden pada musim tanam III adalah sebesar Rp 3.162.500. Sehingga total penerimaan usahatani bawang merah Lokal Topo Rp 6.879.484/tahun.

\subsection{Pendapatan Usahatani Bawang Merah Lokal Topo}

Pendapatan usahatani bawang merah lokal Topo merupakan selisih antara total penerimaan yang diterima dari hasil usahatani bawang merah lokal Topo dengan total biaya produksi yang dikeluarkan. Rata-rata pendapatan usahatani bawang merah lokal Topo dapat dilihat pada Tabel 3 dibawah ini.

Tabel 3. Rata-rata Pendapatan dan R/C Ratio Usahatani Bawang Merah Lokal Topo di Kelurahan Afa-afa.

\begin{tabular}{lc}
\hline \multicolumn{1}{c}{ Uraian } & Nilai/Tahun/Petani (Rp) \\
\hline Penerimaan & 6.879 .484 \\
Total Biaya & 1.629 .149 \\
Pendapatan & 5.250 .334 \\
R/C ratio atas biaya total & 4,22 \\
\hline Sumber : Data Primer Diolah 2020 &
\end{tabular}

- Berdasarkan Tabel 3, dapat dijelaskan bahwa rata-rata pendapatan petani responden di Kelurahan Afa-afa dalam satu tahun (selama tiga musim tanam) adalah sebesar Rp 5.250.334 yang diperoleh dari rata-rata-rata penerimaan sebesar Rp 6.879.484 dikurangi dengan rata-rata biaya total (biaya produksi) sebesar Rp 5.250.334.

Sedangkan untuk mengetahui apakah usahatani bawang merah lokal Topo yang diusahakan petani di Kelurahan Afa-afa tersebut menguntungkan atau merugikan, maka digunakan analisis $\mathrm{R} / \mathrm{C}$ rasio yang merupakan perbandingan antara penerimaan dan biaya. Tabel diatas menunjukan bahwa varietas bawang merah lokal Topo yang diusahakan oleh petani responden di Kelurahan Afa-afa layak diusahakan setelah diketahui nilai $\mathrm{R} / \mathrm{C}$ sebesar 4,22. Berdasarkan kriteria jika R/C > 1, maka usahatani tersebut menguntungkan, sehingga setiap Rp 1 biaya yang dikeluarkan oleh petani bawang merah lokal topo akan mendapatkan penerimaan sebesar Rp 4,22.

\subsection{Analisis Tingkat Kesejahteraan Rumah Tangga Petani Bawang Merah Lokal Topo}

Menurut Disha (2019), Kesejahteraan adalah suatu kondisi dimana seluruh kebutuhan jasmani dan rohani dari rumah tangga tersebut dapat dipenuhi sesuai dengan tingkat hidup kesejahteraan rakyat dapat diamati dari berbagai aspek yang spesifik yaitu ke-tujuh indikator menjadi kriteria BPS (Badan Pusat Statistik) 2014, diantaranya kependudukan, kesehatan dan gizi, pendidikan, ketenagakerjaan, pola konsumsi, perumahan dan lingkungan, sosial dan lain-lain.

Ke-tujuh indikator tersebut, masing-masing mempunyai komponen pertanyaan yang bervariasi jumlahnya, setiap komponen pertanyaan memiliki 3 pilihan jawaban tujuannya agar responden dapat memilih sesuai dengan kondisi yang dialaminya, yang mana jika responden memilih obsen a, nilainya 3 , obsen b nilainya 2 dan obsen c nilainya 1. Selanjutnya nilai dari komponen jawaban tersebut dijumlahkan sehingga dapat diketahui jumlah total pada pada masing-masing indikator, lalu dari jumlah total tersebut kemudian di klasifikasikan ke dalam tiga kelas yaitu baik dengan skor 3, cukup dengan skor 2 dan kurang dengan skor 1, setelah masing-masing komponen pertanyaan diklasifikasikan dengan skor tersebut, maka dijumlahkan skor setiap indikator sehingga menghasilkan total skor. Total skor yang dihasilkan dari skor ke-tujuh indikator lalu dikelompokkan dalam dua klasifikasi yaitu sejahtera dan tidak sejahtera. Berdasarkan hasil penelitian pada petani bawang merah lokal Topo di Kelurahan afa-afa Kecamatan Tidore Utara, yakni sebaran petani responden berdasarkan tingkat kesejahteraan menurut BPS (Badan Pusat Statistik) 2014 dapat dilihat pada Tabel 4 berikut. 
Tabel 4. Sebaran Petani Responden Berdasarkan Tingkat Kesejahteraan Menggunakan Indikator BPS (Badan Pusat Statistik) 2014

\begin{tabular}{lccc}
\hline \multicolumn{1}{c}{ Klasifikasi } & Jumlah (Orang) & Persen (\%) & Skor \\
\hline Sejahtera & 30 & 93,75 & $15-21$ \\
Tidak Sejahtera & 2 & 6,25 & $7-14$ \\
\hline Jumlah Total & $\mathbf{3 2}$ & $\mathbf{1 0 0}$ & \\
\hline Sumber : Data Primer Diolah 2020 & &
\end{tabular}

Dilihat dari Tabel 4 diatas, dapat jelaskan bahwa petani termasuk dalam klasifikasi sejahtera sebanyak 30 orang $(93,75 \%)$ dengan skor 15-21, sedangkan petani yang termasuk dalam klasifikasi tidak sejahtera sebanyak 2 orang $(6,25 \%)$ dengan skor 7-14 Selain itu jika dilihat dari karakteristik petani responden yang sebagian besar berada pada usia produktif, sehingga masih memiliki semangat dan tanggung jawab besar dalam mengembangkan usaha, meskipun sebagian besar petani responden memiliki jumlah tanggungan keluarga yang besar, akan tetapi dari usia anggota keluarga yang sudah siap bekerja akan terdorong bekerja untuk kesejahteraan keluarga.

\section{PENUTUP}

\subsection{Kesimpulan}

Berdasarkan hasil penelitian yang dilakukan terhadap Analisis Pendapatan dan Tingkat Kesejahteraan Petani Bawang Merah Lokal Topo di Kelurahan Afa-afa Kecamatan Tidore Utara Kota Tidore Kepulauan, maka dapat diambil kesimpulan yaitu:

1. Rata-rata penerimaan yang diperoleh petani bawang merah lokal Topo di Kelurahan Afa-afa sebesar Rp 6.879.484/tahun, dengan biaya produksi rata-rata sebesar Rp 1.629.149, sehingga rata-rata pendapatan yang diperoleh petani bawang merah lokal Topo sebesar Rp 5.250.334/tahun. Bawang merah lokal Topo layak diusahakan oleh petani responden di Kelurahan Afa-afa layak setelah diketahui nilai R/C sebesar 4,22.

2. Berdasarkan hasil penelitian rumah tangga petani bawang merah lokal Topo di Kelurahan Afaafa Kecamatan Tidore Utara Kota Tidore Kepulauan bahwa petani bawang merah lokal Topo

4.2. Saran masuk dalam klasifikasi sejahtera yaitu sebesar 93,75 persen.

1. Bagi Dinas Pertanian Kota Tidore Kepulauan, diharapkan dapat meningkatkan kegiatan penyuluhan mengenai budidaya khususnya tanaman

2. Bagi peneliti lain disarankan kedepannya melakukan penelitian yang membahas mengenai saluran tataniaga bawang merah lokal topo di Kota Tidore Kepulauan dan perbandingan pendapatan bawang merah lokal topo yang dijual dengan satuan ikat (panen pada usia muda) dan satuan Kg (Panen pada usia tua) pada petani di Kelurahan afa-afa Kecamatan Tidore Utara Kota Tidore kepulauan.

\section{DAFTAR PUSTAKA}

Arikunto, S. 2002. Metodologi Penelitian. PT. Rineka Cipta. Jakarta.

BPTP Maluku Utara. 2018. Bawang Merah Topo, Varietas Unggul Lokal Tahan Ulat. Dikutip November 2019. (http://malut.litbang.pertanian.go.id/index.php/berita/666-bawang-merah-topovarietas-unggul-lokal-tahan-ulat).

Badan Pusat Statisik. 2017. Luas Panen dan Jumlah Produksi Tanaman Bawang Merah Menurut Kecamatan di Kota Tidore Kepulauan,. 2017. Kota Tidore Kepulauan. https://tikepkota.bps.go.id/dynamictable/2018/09/30/96/luas-panen-dan-jumlahproduksi-tanaman-bawang-merah-menurut-kecamatan-di-kota-tidore-kepulauan2017.html. Diakses pada 1 Januari 2020.

Badan Pusat Statisik. 2016. Produksi Tanaman Sayuran Menurut Kabupaten/Kota di Provinsi Maluku Utara, Tahun 2015. Provinsi Maluku Utara https://malut.bps.go.id/dynamictable/2016/07/24/159/produksi-tanaman-sayuran 
menurut-kabupaten-kota-di-provinsi-maluku-utara-tahun-2015.html. Diakses pada 1 Januari 2020.

Disha, S.A. 2019. Pendapatan dan Tingkat Kesejahteraan Rumah Tangga Petani Sayuran di Kecamatan Gisting Kabupaten Tanggamus. Skripsi. Jurusan Agribisnis Fakultas Pertanian Universitas Lampung.

Muhammad, M dan Ekaria. 2019. Strategi Pengembangan Usaha Bawang Merah Lokal Topo di Kecamatan Tidore Utara Kota Tidore Kepulauan. Munawir Muhammad dan Ekaria. Jurnal Agribisinis Perikanan. Vol. 12. No. 2: 209-219.

Muhammad, Munawir, Fatmawati Fatmawati, and Abdul Haris Din. "Analysis of Distribution and Marketing Margin of Topo Local Shallots in North Tidore District, Tidore Islands City." Agrikan: Jurnal Agribisnis Perikanan 13.2 (2020): 334-343.

Sari, D.K., Haryono, D dan Rosanti, N. 2014. Analisis Pendapatan dan Tingkat Kesejahteraan Rumah Tangga Petani Jagung di Kecamatan Natar Kabupaten Lampung Selatan. Jurnal JIIA. Volume 2. No. 1.

Soekartawi. 2003. Prinsip dasar Ekonomi Pertanian (Teori dan Aplikasinya). PT Raja Grafindo Persada. Jakarta.

Sugihono, C., Assagaf, M., Saleh , Y dan Notosusanto, A. 2010. Inovasi Teknologi Bawang Merah CV.Topo Sebagai Varietas Unggul Lokal Spesifik Maluku Utara. Balai Pengkajian Teknologi Pertanian Maluku Utara. .

Thresia, M.W. 2017. Analisis Pendapatan Usahatani Kedelai Di Kecamatan Berbak Kabupaten Tanjung Jabung Timur. Skripsi. Program Studi Agribisnis Fakultas Pertanian Universitas Jambi. 